\title{
Assessing the Relevance of Educating the Elderly on Their Feeding Pattern and Food Security in Municipality
}

\author{
Nana Asimah Adam-Yawson ${ }^{1} \quad$ Evelyn Kissi $^{2} \quad$ Victoria Aba Mensah ${ }^{1}$ \\ 1.Education and Professional Studies Department, Komenda College of Education, Komenda \\ 2.Vocation and Technical Department, Komenda College of Education, Komenda
}

\begin{abstract}
The elderly are particularly vulnerable to food and food security due to their reduced income and physical capabilities, as well as increased rate of chronic diseases, which predispose them to hardship and poverty. The study sought to assess the feeding habits and challenges of the elderly people in Komenda-Edina-Eguafo-Abrem (K.E.E.A.) Municipality in The Central Region of Ghana. It also aimed at examining the eating pattern of the elderly, factors affecting the feeding habit of the elderly, roles of caregivers to the elderly, and satisfaction of the elderly with the level of care given to them in their feeding. The study adopted cross sectional, noninterventional and descriptive research design. Snowball sampling technique was used to sample 100 elderly and 100 care givers from a population of 6,315. Interview was used to solicit for information from the focus group. The study revealed that income, poverty, commitment of caregivers and ignorance of nutrient values in food limited the ability of the elderly to adopt improved feeding habit. Due to these factors, majority of the elderly were not able to adopt regular eating style, and eat the recommended three regular meals per day. Some of the challenges encountered by the care givers were erratic flow of remittance, having weak strength to continue providing caregivers support and bearing the high cost of caring for the elderly. The study recommends that frantic efforts should be made by stakeholders in K.E.E.A. Municipality to help improve the general standards of living of the elderly in the Municipality. Non-Governmental Organisations (NGOs) caring for the aged and The Social Welfare Department in the K.E.E.A. Municipality should provide social, technical, and material support to the elderly. The Government of the Republic of Ghana Should increase the LEAP funds meant for the vulnerable aged. Guidance and Counselling professionals should extend their community services and social supports to the elderly in K.E.E.A. Municipality and their caregivers.
\end{abstract}

Keywords:Nutrition, octogenarians, dependent, caregivers, premature, vulnerable, feeding, elderly persons, eating pattern, infections.

DOI: $10.7176 / \mathrm{JEP} / 12-10-05$

Publication date: April $30^{\text {th }} 2021$

\section{Introduction}

Eating is an indispensable activity of human beings to live and function effectively as normal human beings. Maintaining appropriate nutrition is essential for healthy living and ensuring maximum resistance to infection and disease (Morley, 2001). Morley further indicated that eating is not only paramount for physical survival but also holds psychological and social significance for persons of every age group. Bozzetti (2003) supported this assertion made by Morley (2001) that social life of the adult is built to a great extent around the pleasures of foods and drinks. Bozzetti (2003) further emphasised that people frequently eat for social reasons rather than only physiological needs. Without food in its balanced composition will make the individual malnourished and incapable to grow and live a healthy life.

Internationally, the aging population is extremely different, ranging from fit, active healthy octogenarians to extremely weak, totally dependent people with chronic diseases and severe disabilities (United Nations 2005). United Nations (2007) commented that the aging population was increasing, about $16.0 \%$ of the population was over 65 years and two per cent were over 85 years. These figures were predicted to rise dramatically in the next 30 years. Morley (2002) also indicated that the human body changes negatively as one gets older. A less efficient immune system means, older people are more vulnerable and prone to persistent illness and infections usually at old age. Morley (2002) asserted that the digestive system of the elderly works more slowly, so constipation and bowel problems are more common. The elderly are assumed to take in very little water making their bodies almost always dry. The elderly lose muscle and bone strength, making them more likely to fall over with fractured bones and weak muscles. Less efficient kidneys means that urine is less concentrate, as the elderly may be less likely to realise they are thirsty and dehydration is more common as a result frequent urination at earlier age reduces drastically. The elderly men are usually prone to prostate cancer urine track diseases.

The study of the elderly has become major concern to many academic disciplines including psychology and counselling. Donald Supper's Developmental (Self-concept) Theory as cited by Buku (2016) indicated that they are in the declined age (over 65 years) Buku (2016) continued that they experience awareness of their needs to accept their fate or situation as it may be. With such deteriorating age there are no meaningful decisions that will be very beneficial to the elderly. Donald Supper referred to this last stage of human development in his theory as 
the stage of disengagement. These disconnection stages clearly indicate that the elderly have totally declined in age, strength, and the ability to be very independent from relatives. .

Backstrom et al (2007) asserted that some elderly people depend on caregivers to take care of them. Some elderly people require complete assistance from others to receive food into their mouth. Such people are considered completely dependent with regard to feeding and basic caregiving. In Ghana the situation is more serious with some elderly males who are without wives as majority of male elderly depend on their wives for their feeding. Backstrom et al (2007) cited elderly people to be usually suffering from dementia, stroke and multiple sclerosis. Morley (2003) further explained feeding as the series of sequential steps necessary to get the food into the mouth. When a person is totally dependent and must be fed by caregivers, the caregivers needs to coordinate their behaviours in both technical and deceitful ways. Poor diet of the elderly is related to illness, premature death and many health conditions which can lower the quality of life for elderly people. The elderly will become under-nourished if the older people do not eat enough balanced diets. Adequate nutrition and good health are the rights of all individuals, which form the basis for the development of the nation.

Mba (2005) claimed that the aging population forms a heterogeneous group of people that vary greatly in their social, economic and lifestyle situations, functional capacity and physical conditions. The functional capacity and health of the elderly depend on their nutritional status and food security, which are the foundation in determining nutritional well-being. Farmers in developing nations such as Ghana who farm on subsistence level where propensity to save towards old age is very minimal are always at risk. The elderly are particularly vulnerable to food insecurity due to their reduced income and physical capabilities, as well as increased rates of some chronic ill health, which predispose them to poverty. Eating well balanced diet means the one has the required amount of energy (calories) and nutrients (protein, fats, carbohydrates, fibre, vitamins and minerals) that they need every day to maintain their body processes and to protect their body from ill health. A nutritionally adequate diet is considered critical component of a lifestyle aimed at promoting healthy and aging (Bartali et al 2003). Roberts \& Rosenberg (2006) claimed the impact of advancement in paying for medical bills, paramedical sciences and technology is an increase in life expectancy globally.

The elderly can become frail as they age, especially when dealing with debilitating conditions like fibromyalgia, arthritis, vertigo (dizziness) and disability. Physical pain and poor strength can make even simple tasks (opening a can, peeling fruits and standing up long enough to cook a meal) too challenging. The negative effects t6hat aging and disability can have on the feeding of the elderly person living in nextended care facilities is well established (Beck, Ovesen \& Schroll, 2001; Beck \& ovesen, 2002) sensory changes associated with the aging process can influence patterns of intake of nutria. The causes of the physiological anorexia of aging include changes in taste and smell and a decrease in adaptive relaxation of the fundus of the stomach, which leads to stomach upset. This is possible because the body organs of the aged become weaker as they get old.

There is high risk of swallowing difficulties among the older people. Dysphagia is very common in older persons with neurological diseases such as stroke, Parkinson's disease and dementia. People with swallowing problems are more likely to be under-nourished or to be dehydrated and are at risk of breathing in. Wilson and Morley (2003), claim that the aged usually seen hovering with the next spoonful exacerbates swallowing problems. The elderly with swallowing problems may include those with cancer, stroke affecting the motor cortex or the deglutition centre, Parkinson's disease, arteritis and some muscular disorders. Elderly people who have suffered stroke have often increased difficulties in swallowing, due to paresis (Terre \& Mearin, 2012), and are at risk of insufficient dietary intake (Kagansky et al, 2005). Stroke may also include decreased impaired selffeeding ability related to impairment in the arms and visual deficits (Perry, 2001a, 2001b; Perry \& Mclaren, 2000; Westergren, 2006, Westergren, Ohlsson \& Hallberg, 2002).

Mba (2010) was of the view that, in Ghana, about five per cent of the population constitute the elderly, with the proportion expected to increase in subsequent years. What is more alarming about this demographic trend according to Mba (2010) was the reflex pattern of attending to maternal and child health to the exclusion of other population groups that need to be addressed. In such instance government needs to spend much budgetary allocation to take care of the elderly. In Ghana since the introduction of National Health Insurance Scheme (NHIS) the elderly above 60 years are not expected to pay anything. These and many other are among the factors that have led to the increase in the government's budgetary allocation for the elderly. The elderly usually has low economic status as a result of reduced work capacity (McCusker, Kakuma \& Abrahamowicz, 2002). Many of the elderly survive under the benevolence of family, community and charitable organisations. They are most unlikely to eat balanced diets to meet the nutritional needs of their changing physiologic state. This makes them vulnerable to poor nutrition and unhealthy living. The most seriously affected elderly in Ghana are those working in the informal sector whose propensities to save towards their old ages are questionable. This is because majority of them work for survival but nothing to save for the future.

Malnutrition can bring about morbidity, mortality and being hospitalised for longer period with functional disabilities and physical complications. It can also result in oral health, physical impairments, early satiety, taste and small changes (Hall \& Brown 2005). Older adults experience less of a feeling of hunger and experience a 
feeling of fullness more quickly as compared to younger adults (younger than 65 years old). Elderly persons are at high risk for eating and feeding difficulties and inadequate food and fluid intake. Amelia (2004) says depending on the severity of their cognitive impairment, they may forget to eat, forget they have eaten, and fail to recognise food or eat things that are not wholesome to be considered as food. They may have difficulty with specific tasks (e.g. removing plate covers and wrappings, knowing what the utensils are for and using them, moving food or fluid to their mouth, chewing and swallowing). They may have difficulty initiating the eating process or they may start eating, get distracted, and fail to finish with what they will be doing (Amelia 2004). At times the elderly may chew fish or stew that they are expected to consume their food with and turn round to complain that they were served food without fish or stew.

The elderly are said to be vulnerable because of lack of universal social security system and fragmentation of families stemming from increasing economic hardship and stagnation and weakening of family organisation and kinship networks in Ghana (Mba 2004a). In Ghana the ability to save towards old age were very low or not existing in the low-income earners. Asenso-Okyere and Suresh (2008) stated that the elderly in Ghana is mostly experiencing food insecurity, which affects spans across food availability, accessibility and utilisation. The accessibility is an index which includes the functional capabilities to obtain the food, whereas the utilisation considers the physiological ability to digest and assimilation of nutrients for proper health (Bellin-Sesay, 2008). Joyce, Keeler, Shang \& Goldman (2005) commented that the elderly succumb to economic pressures that take them out of the home for substantial period of time. They continued that, these elderly are not the most attuned to the modern health requirements.

The absence of the middle generation also means that the elderly who need care are frequently looked after by adolescent grandchildren who are left at home to care for the elderly. Many adult may be actively working outside where their parents live and leave their children to take care of their elderly parents on their behalf. These developments have serious implications for the health and wellbeing of the elderly and the adolescent usually girls who are supposed to be in schools. It may even affect the school going of the grandchildren who are expected to take care of the elderly. The increasing difficulties of the elderly are frequently attributed to modernisation and its attendants undermining of family structures and lineage systems Mba (2004b). The researcher believed that there are inverse relationship between modernisation and family support for the elderly, resulting in growing incidence of low levels of wellbeing among the elderly people. Westenhoefer (2005) claims that women older than 50 years who are not very active should consume about 1,600 calories a day to maintain their weight and metabolism. Eating 1,800 calories if one is moderately active and closer to 2,000 if one is engaging in an active lifestyle and exercises regularly are very important. Sedentary men should eat about 2,000 calories a day, 2,200 to 2,400 if they are moderately active and between 2,400 to 2,800 if they are active most days. Westenhoefer (2005) recommends two to four servings of fruits and three to five serving of vegetables every day to help restore their lost energy.

The main concern in the elderly is the reported decline in food intake and the loss of the motivation to eat (Donini et al 2003). This suggests the presence of problems associated with the regulation of energy balance and the control of food intake. Donini et al (2003) continued that, a reduced energy intake results to body weight loss may be caused by social or physiological factors or a combination of both. Attention needs to be paid to any constraints to care and not just to the nutritional aspects of foods. Chen et al (2005) attributed elderly problem to poverty or low income as factor that impacts upon feeding in the elderly people living in their own homes. Also, the drugs which doctors' prescribe on their hospital visits of the elderly or in-home medical equipment can be very costly to the elderly. However, El-Solh (2011) indicated that it is also physically and emotionally demanding. Caregivers stress is the emotionally and physical strain of caregivers which can take many forms.

During 2008 the government of Ghana through Ministry of Gender Children and Social Protection introduce Livelihood Empowerment Against Poverty (LEAP) to mitigate and support the elderly who are hard hit by poverty. LEAP is a cash transfer programme from the government. Since the introduction of this programme, it has benefited over 213,000 all over the year. Despite such coverage much need to be done to benefit greater majority or the aged poor who are finding it extremely difficult to have three nutritious feeding daily. Also the amount given to the elderly poor are assumed not to be able to solve their feeding problems. Though the minister had promised to cover most elderly poor but yet to realise the government's dream of wider coverage of the elderly poor. Beneficiaries of LEAP include persons aged 65 years and above without any form of appropriate support. A beneficiary is given an amount of sixty four (64) Ghana Cedis, (about eleven dollars) two beneficiaries are given seventy six (76) Ghana Cedis (about fourteen dollars) three beneficiaries are given eighty eight (88) Ghana Cedis, (about sixteen dollars) and four and above are given one hundred and six (106) Ghana Cedis (about twenty dollars) quarterly. Even this may not be very regular as such amount is given quarterly.

During aging, body components undergoes changes from increasing body weight in the first part of life which stabilises in late middle age and decreases in very old people (Dey, Rothenberg, Sundh, Bosaeus \& Steen (2001). Seventy five years of age seems to be a turning point when weight starts to decrease (Perissinotto, Pisent, 
Sergi, Grigoletto \& Enzi 20002). Bozzetti (2003) supported that there are gradual decrease in total body water from adulthood to old age, constitutes less than fifty per cent $(50 \%)$ of body weight which is below the normal range of $50 \%$ to $60 \%$. With advancing age a severe reduction in the flow of saliva is observed (Nagler, \& Hershkovich 2005). At old age many Ghanaian elderly may be staying with their grandchildren who are likely to be in the school going ages and at times affect their school attendance, performance and their attitudes towards school going as it may be very difficult to combine serious academic work to caregiving to the elderly. When the problem is not appropriately handle may also pose further problem which may become very difficult to handle. The purpose of this study was to look at the background characteristics of the elderly, their pattern of eating and the role caregivers play on taking care of the elderly and the influence on the caregivers.

\subsection{Objectives}

1. Identify the background characteristics of the selected elderly and the aged in the KEEA Municipality

2. Find out the eating pattern of the selected elderly and the aged in the KEEA Municipality.

3. Investigate the role of caregivers of the selected elderly and the aged in KEEA Municipality.

\subsection{Research Questions}

1. What are the background characteristics of the selected elderly and the aged in the KEEA Municipality?

2. What are the eating patterns of the selected aged and the elderly in the KEEA Municipality?

3. What are the roles of the caregivers of the selected aged and the elderly in KEEA Municipality?

\subsection{Research Design}

The research design used for the study was cross-sectional non-interventional descriptive research design. Creswell \& Creswell (2018) defined research design as the overall framework which guides the processes for collecting and analysing data for particular research. Biemer and Lyberg (2003) explained that cross-sectional research design is used when researcher intends to collect data about a phenomenon at a single point in time. This research design was used because the researchers did not intend to do a trend analysis of the feeding patterns of the elderly but rather describe the overall picture on the feeding habits and feeding challenges of the elderly as described by the respondents without tracking changes in the research subjects over some time and its influence on the education of the adolescent caregivers.

\subsection{Population}

The population for the study comprised elderly persons aged 60 years and above in the KEEA Municipality in the Central Region of Ghana and their caregivers. It is estimated that there are a total of 6,315 (4,235 females and 2,080 males) elderly persons in KEEA Municipality area (KEEA Municipal Assembly 2006 data). The implication is that $3.6 \%$ of the population of KEEA Municipality is within the elderly group. The population of caregivers were not easy to compile for the simple reason that while some of them claim that they had no caregivers others were taken care of by any of the household members who happened to be present in the house regularly. This is because the caregivers may also be in serious business and performing the caregiving as parttime duties and may at times be absent when the elderly is seriously in need of caregiving services from the care giver.

\subsection{Sample and Sampling Techniques}

A sample consists of a carefully selected subset of the unit that comprises the population. Since in all the communities in KEEA Municipality the elderly persons and their caregivers could not be included in the study, 10 communities out of the 158 were randomly sampled. Simple random technique was used to sample the communities. The researchers used quota and snowball sampling techniques to get the sample size of 100 elderly and their caregivers.

\section{Instrument for Data Collection}

The instrument the researchers used for data collection was interview. The researchers got in touch with an elderly person and afterwards directed them to other elderly persons and caregivers for the interview steered by interview guide. The researchers gave orientation to ten researcher assistants to assist in the interview of the elderly. Borg \& Gall (2003) Weiten (2007) Creswell \& Creswell (2018) commented that interview involves the collection of data through direct verbal interactions between individuals (interviewer and interviewee). 


\section{Data Analysis}

3.1 Research Question 1.

What are the background characteristics of the selected elderly and the aged in the KEEA Municipality?

Bozzetti (2003) expressed that the biographic information of the elderly explains differences and similarities in their feeding issues. Some of the issues considered under the section were sex, age, level of education and occupation. Morley (2002) indicates that each gender group has its own peculiar feeding issues with respect to the elderly. When the aged are far more than 60 their problems also get more complicated.

Table 1: Age Characteristics of the Elderly

\begin{tabular}{ccc}
\hline Age cohorts (years) & Frequency & Percentage \% \\
\hline $60-65$ & 33 & 33.0 \\
$66-70$ & 28 & 28.0 \\
$71-75$ & 21 & 21.0 \\
$76-80$ & 12 & 12.0 \\
Above 80 & 6 & 6.0 \\
\hline Total & $\mathbf{1 0 0}$ & $\mathbf{1 0 0 . 0}$ \\
\hline
\end{tabular}

Field data 2019

Data from table 1 shows that $33.0 \%$ of the elderly were aged within 60-65 years, 28 per cent were within 66-70 years of age, while $21.0 \%$ were within $70-75$ years. $12.0 \%$ and $6.0 \%$ were for the ages $76-80$ and above 80 years and respectively. This distribution of the results show that the ages of the sampled elderly were negatively sloped meaning their proportion is within the various age group which decreases as the ages increase. The study further examined the occupational characteristics of the elderly. The focus was on the type of occupation they were engaged in before retiring. This was necessitated by knowing the physical toll of occupation on people which will help shape their health and feeding habits. Bartali et al (2003) claimed that people's engagement in economic activities that demand huge physical strength influence their health and feeding habit during their elderly years. For instance someone whose work requires much strength is expected to consume much carbohydrate food. Also the elderly who were working in the informal sectors before retirement were also in financial crisis during their old age because in Ghana those who work in the informal sector are not contributors to the Social Security and National Insurance Trust (SSNIT) who take care of the retirement of workers in the formal employment.

Table 2: Occupation of the Elderly of the Sampled Respondents

\begin{tabular}{lcc}
\hline Occupation & Frequency & Percentage (\%) \\
\hline Farming & 18 & 18.0 \\
Fishing & 16 & 16.0 \\
Artisans & 10 & 10.0 \\
Trading & 21 & 21.0 \\
Public Service & 28 & 28.0 \\
Others & 7 & 7.0 \\
\hline Total & $\mathbf{1 0 0}$ & $\mathbf{1 0 0 . 0}$ \\
\hline
\end{tabular}

Field Data 2019

Data in table two shows that $28.0 \%$ of the respondents were public servants, $21.0 \%$ were traders, $10.0 \%$ were artisans while $18.0 \%$ and $16.0 \%$ engaged in farming and fishing respectively with the remaining $7.0 \%$ as workers from private security, private radio presenters etc. The study further requested the elders to indicate their source of income and their regularity were critical in ensuring good quality caregiving to the elderly. Backstrom et al (2007) argued that the elderly with high income levels are better cared for and fed well than those with low or erratic flow of income. Table 3 presents detailed results on the source of income of the respondents.

Table 3: Sources of Income for the Elderly

\begin{tabular}{lcc}
\hline Occupation & Frequency & Percentages \% \\
\hline Pension & 29 & 29.0 \\
Remittances & 52 & 52.0 \\
Economic Activities & 11 & 11.0 \\
Caregivers & 8 & 8.0 \\
\hline Total & $\mathbf{1 0 0}$ & $\mathbf{1 0 0 . 0}$ \\
\hline
\end{tabular}

\section{Field Data 2019}

The study revealed that $52.0 \%$ of the elderly depend on remittances from their relatives as their source of income for their upkeep, $29.0 \%$ of the elders had monthly pension payments as their source of income, $11.0 \%$ still rely on their economic activities for their upkeep while eight per cent depend on caregivers for their survival. This figure indicates that more than fifty per cent are not independent and therefore complain of irregular and unreliable flow of income as their sources of income, $33.0 \%$ complained of inadequate size of income, $17.0 \%$ 
admitted their satisfaction with the size and regularity of their income. The irregularity and smallness of their income are likely to affect the quality of care and feeding issues of the elderly in the Municipality. This is likely to increase the burden on caregivers which may also affect their commitment and quality of care towards the elderly. Backstrom et al (2007) indicated that regular financial flow towards the upkeep of the elderly is critical for improving the quality of care of the elderly.

Also, the irregular flow and small size of income to the elderly is likely to affect their food security which is a critical component in their upkeep and caregiving. Mba (2005) claimed that the elderly are particularly vulnerable to food insecurity due to their reduced income and physical capacities as well as increased rate of some chronic, predispose them to poverty.

\subsection{Research Question 2}

What are the eating patterns of the selected aged and the elderly in the KEEA Municipality?

The purpose of this question is sought to examine the eating patterns of the elderly in the KEEA Municipality and to elicit how the selected elderly eat and which type of food they eat in the KEEA Municipality and with whom they eat. This is important because the eating habit of the elderly play critical role in their health conditions and continuous living of the elderly. Some of the issues considered under the section were regularity of eating, number of times of eating and consumption of multivitamin supplements. This was very imperative because the adoption of regular eating patterns help to ensure easy digestion and metabolism which enables people especially the elderly to derive maximum nutrients from food to improve their health (Crogan et al 2001).

The study revealed that $67.0 \%$ (great majority) of the elderly denied having regular times of eating, whereas $33.0 \%$ indicated having regular eating pattern. This implies that the majority of the senior citizens are not able to adopt regular eating style. This finding agrees with the assertion made by Mba (2010) that most elderly in developing economies are unable to adopt regular eating habit because of poverty, little regards to time in eating and poor social interventions to the elderly. The regularity of eating was further examined in terms of their level of education of the elderly. This became necessary because Mba (2010) asserted that elderly with high levels of education had better knowledge in nutrition and understood the importance of adopting regular eating pattern than those with low levels or no formal education. It is also true that those with high level of education are likely to enjoy high incomes as pensioners. Table 4, presents a cross analysis between levels of education of the elderly and regularity time of eating.

Table 4: Level of Education and Adoption of Regular Eating Habit

\begin{tabular}{|c|c|c|c|}
\hline \multirow{2}{*}{$\begin{array}{l}\text { Education Level } \\
\text { Habit Total }\end{array}$} & Regular & Eating Habit Irregular & \multirow[b]{2}{*}{ Number (\%) } \\
\hline & Number (\%) & Number (\%) & \\
\hline No formal Edu. & $3(3.0)$ & $16(16.0)$ & $19(19.0)$ \\
\hline Basic Edu. & $5(5.0)$ & $36(36.0)$ & $41(41.0)$ \\
\hline "O” Level & $15(15.0)$ & $6(6.0)$ & $21(21.0)$ \\
\hline "A" Level/Tertiary & $10(10.0)$ & $9(9.0)$ & $19(19.0)$ \\
\hline Total & $33(33.0)$ & $67(67.0)$ & $100(100.0)$ \\
\hline
\end{tabular}

Source Field Data 2019

From table 4, out of the 19 who had no formal education 3 have regular eating habits with 16 having irregular eating habits. 41 of the respondents had basic education of which 5 of them had regular eating habits with 36 had irregular eating habits. Also, 21 of the elderly possess "O" Level education, 15 have regular eating habit with the remaining 6 having irregular eating habits. Finally, 19 of the elderly have either "A" Level or Tertiary education, 10 of them have regular and 9 with irregular eating habits. This confirms the declaration made by Mba (2010) that the elderly with high levels of education adopted more regular feeding patterns than those with low levels of education. The table confirms that those with "O" Level and above have regular eating habits.

The respondents were requested to indicate their reasons for not adopting regular time of eating.

The results are presented in Table 5. 
Table 5: Reasons for the Non-adoption of Regular Eating Patterns

\begin{tabular}{lcc}
\hline Reasons & Frequency & \\
Percentages & 40 & 40.0 \\
Poverty & 21 & 21.0 \\
Not aware of its importance & 19 & 19.0 \\
Not having the appetite to eat & 12 & 12.0 \\
Forgetfulness & 8 & 8.0 \\
Busy schedule of caregivers & $\mathbf{1 0 0}$ & $\mathbf{1 0 0 . 0}$ \\
\hline Total & & \\
\hline Source: Field Survey, 2019 & & \\
\hline
\end{tabular}

Data from table 5, shows that $40.0 \%$ attributed their non-adoption of regular eating habit to poverty, $21.0 \%$ are not aware of its importance, $19.0 \%$ does not have the appetite to eat, $12.0 \%$ was due to forgetfulness while $8.0 \%$ selected busy schedule of their caregivers. With these findings Ree (2007) claimed that income levels of elders influence their food choices as against the availability of the resources to purchase a higher quality food at the regular intervals and awareness of nutritious alternative. Also, some food may look very rich but nutrients contents might be very low.

\subsection{Research Question 3}

What are the roles of the caregivers of the selected aged and the elderly?

The third research question sought to examine the roles of caregivers in the feeding of the elderly in the KEEA Municipality. Simmons and Schnelle (2004) found out in their study that the role of caregivers do most things for the elderly including bathing, changing their clothing, feeding those who do not have dependable use of their limbs or bowel and bladder control. Not only might feeding be required of caregivers, but preparation of food could be necessary too. Some of the issues considered under the section were the relationship between the caregivers and the elderly, services the caregivers provided for the elderly, and the challenges caregivers encountered in performing their roles to the elderly. The relationship between the caregivers and the elderly they cared for was also examined. Christensson et al (2002) commented that professional caregivers who perform their roles for economic rewards are more committed to the upkeep of the elderly than those who perform such roles on social reasons. In Ghana, professional caregivers are not very common to come by but commonly those who upkeep the elderly on social reasons are very common. Nicholas (2006) on the contrary expressed that the elderly who receive caregiving support from their direct wards receive better treatment and more attention than those who are handled by other family members and extended relations.

Satisfaction of the Elderly about Their Food from Their Caregivers.

The researchers wanted to know the satisfaction of the elderly about the type of food their Caregivers give them the result is given in figure 1 .

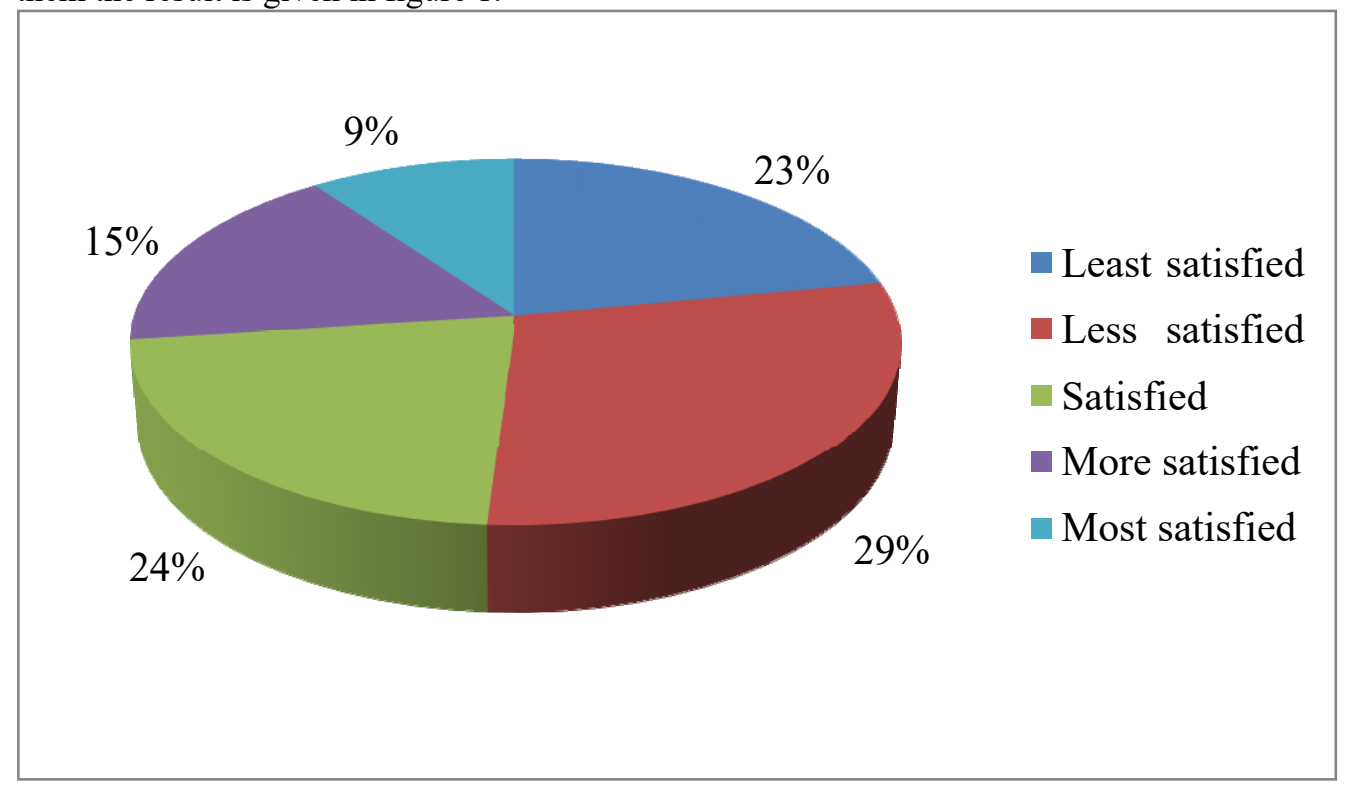

\section{Field Data 2019}

Figure 1 shows that $23.0 \%$ of the selected elderly were least satisfied with the type of food served them, $29.0 \%$ were less satisfied whereas $15.0 \%$ and $9.0 \%$ were more satisfied and most satisfied respectively. The result indicates that majority $(52.0 \%)$ of the elderly were not satisfied with the type food they were served. Even 
though most $(65.0 \%)$ of the elderly were satisfied with the quality of food, they were not satisfied with the type of food they were provided with. This could be attributed to the differences between the preferred type of food provided for the elderly and the types and the type of food

\section{Summary of Major Findings}

- Majority of the respondents (61 respondents) are between the ages of 60 to 70 years.

- The more people grow the more they either become too fragile to be associated with.

- More than $50 \%$ of the elderly rely on remittances to survive.

- The educated elderly have regular eating habit and take in nutritious food than the uneducated.

- $50 \%$ of the elderly complained of irregular and unreliable flow of remittance from their source of income.

- Majority (67.0\%) of the elderly denied having regular times of eating.

- Majority of caregivers are close relatives as professional caregivers are not very common in Ghana.

- Some of the caregivers are adolescents and teenagers who are in the school going age and as a result affect their school going. Some of the caregivers take care of elderly (usually their grandparents) in the morning before going to school and continue when they return from school.

- Poverty and low incomes from relatives affect their eating habit negatively.

- Majority of the elderly do not have the appetite to eat appropriately very often.

- Majority of them are able to perform basic activities such as bathing, eating, drinking water etc. on their own.

- The caregivers cook food for the elderly, washing of clothes, bathing, feeding, taken them to hospital, provide drugs, and provide psycho-social support by keeping them active.

- There were strict social bond existing between caregivers and the elderly in KEEA.

- Most of the caregivers perform their care services on purely humanitarian grounds.

- Caregivers perform economic activities or schooling alongside caregiving which is likely to affect the quality of care and attention given to the elderly in KEEA Municipality.

- Some caregivers considered the services rendered to the elderly as their responsibility.

\section{The researchers suggested that:}

- The NGOs advocating for the care for the aged (e.g. Help Age Ghana) should assist in establishing aged home like the orphanage to take good care of the elderly.

- The Government of Ghana should establish homes to take good care of the aged.

- The Government of Ghana should also resource Social Welfare and Community Development to extend their regular services to the elderly.

- The Ministry of Gender Children and Social Protection should increase the LEAP funds given to the aged to alleviate their hardship. An amount of about eleven dollars quarterly to the researchers may be woefully inadequate to a household to mitigate their problems.

- Guidance and Counselling services should be extended to cater for the aged earlier enough while they are in active service to plan for their retirement age.

- Guidance and Counselling should be strengthened in the basic schools and the Secondary Schools to sensitize the teenagers and adolescents who are taking care of their parents and grandparents.

- Professional caregiving centres should be established or encouraged in Ghana as it is done in some developed world.

\section{Conclusions}

Changes in the body composition of the elderly influence the nutritional status. Body composition changes during malnutrition with the loss of fat and muscle tissue as well as age. The study found out that the elderly had low levels of education and income, depends largely on remittance. The family systems in Ghana also affected the role and the nature of relationship between caregivers and the elderly. This was because all the caregivers had family relations with the elderly they are caring for. Some of the challenges encountered by the caregivers in providing their role to the elderly were erratic flow of remittance to ensure the good upkeep of the elderly, having little strength to continue providing caregiving support to the elderly and high cost of caring for the elderly. The irregular flows of funds to the poor elderly to the researchers were not the best and need to be increased. The LEAP funds from the government should also be increased.

The Government of Ghana should establish homes to take good care of the aged As the professional 
caregivers are likely to take good care of the aged that what they might possibly have currently. Also, the Government of Ghana should resource The Department of Social Welfare and Community Development to extend their regular services to the elderly who need their services urgently. There should be guidance and counselling services to the elderly to be able to cope with their current situation. It also revealed that some of the caregivers are adolescents who are in the school going age therefore guidance 3 and counselling coordinators should talk on effective time management so as to be able perform their normal duties as caregivers and student life as well. The Central Government should also, try to offer free medical care or subsidise medical care for the elderly.

\section{References}

Amella, E. J., (2004) Feeding and hydration issues for older adults with dementia. In M. Mezey, E., Capezuti \& T. Fulma (Eds.), Care of older adults: Nursing clinics of North America, 39(3), 607- 623 (Retrieved $11 / 18 / 2020)$

Asenso-Okyere, K., \& Suresh, C. B. (2008) Technological tools to address the food crisis, CAB Review: Perspectives in Agriculture, Veterinary Science, Nutrition and Natural Resources, 3(100), 1-11. (Retrieved $10 / 10 / 2020)$

Backstrom, A., Norberg, C., \& Norberg, J., Artificial feeding for several disoriented elderly, Family Physician, 35 (35) 1057-1062. (Retrieved 11/10/2020)

Baltali, B., Salvini, S., Turrini, A., Lauretani, F., Russo, C. R., Bandinelli, S, D’Amicis, A., Palli, D.,Guralnik, J. M., \& Ferrucci, I., (2003), Age and disability affect dietary intake, Journal of Nutrition, 133, 2868-2873 (Retrieved 10/10/2020)

Beck, A. M., Ovesen, L., \& Schroll, M. (2001). A six months' prospective follow-up of 65+-y-old patients from general practice classified according to nutritional risk by the mini nutritional assessment. European Journal of Clinical Nutrition, 55, 1028-1033.

Beck, A. M., \& Ovesen, L., (2002). Body mass index, weight loss and energy intake of old Danish nursing home residents and home care clients. Scandinavian Journal of Caring Sciences, 16, 86- 90.

Bellen-Sesay, F., (2008) Food and nutrition security; The concepthttp://www.univie.ac.at/nutrition/Iva/weltern/GlobalNutrition2008/V1-FoodSecurity- NutritionSurity pdf (Retrieved 11/11/2020)

Biemer, P., Lyberg, L. E., (2003).The survey process and data quality: Introduction to survey quality. New York: Wiley

Borg, W. R., \& Gall, M. D., (2003) Educational research,: an introduction. Englewood Cliffs, NJ: Prentice Hall.

Bozzetti, F., (2002) Nutritional issues in the care of the elderly patient, Critical Review in Oncological Haematology 48, 113-121, (Retrieved 12/12/2020).

Buku, D. K., (2016) Foundations of Guidance and Counselling Benjoy Enterprise Ltd. Asafo- Kumasi.

Chen, C. C., Chang, C. K., Chyun, D. A., McCorkle, R., (2005) Dynamics of nutritional health in a Community sample of American elders. A multi-dimensional approach using roy adaptation model. Advances in nursing science,28, 376-389 (Retrieved 10/10/2020)

Christensson, 1., Unosson, M., \& Ek, A. C., (2002)Evaluation of nutritional assessment techniques in elderly people newly admitted to municipal care. European Journal of Clinical Nutrition, 56, 810-818 (Retrieved $12 / 12 / 2020)$

Creswell, J. W., \& Creswell, J. D., (2018) Research Design, qualitative, Quantitative and Mixed Methods Approaches $\left(5^{\text {th }}\right.$ ed) SAGE Publications, Inc. U.S

Crogan, N. L., Shultz, J. A.,Adams C. E., \& Massey L. K., (2001) Barriers to nutrition care for nursing homes residents, Journal of Gerontological Nursing, 27, 25-31 (Retrieved 10/12/2020)

Dey, D. K., Rothenberg, E., Sundh, V., Bosaeus I., \& Steen, B., (2002). Waist circumference, body mass index, and risk for stroke in older people: A 15-year old longitudinal population studuy of 70-year olds: Journal of American Geriatrics Society,50, 1510-1518 (Retrived 11/11/2020).

Donini, L. M., Savina, C., \& Cannella, C., (2003). Eating habits and appetite control in the eldely: The anorexia of aging. International Psychogeriatric, 15(1), 73-87 (Retrieved 10/10/2020)

El-Solh, A. A., (2011) Association between pneumonia and oral care in nursing home residents Lung 189(3), 173-180 (Retrieved 10/10/2020)

Hall, B., \& Brown, L., (2005), Food security among older adults in the United State, Topics in Clinical Nutrition, 4(20), 329-336 (Retrieved 11/11/2020)

Joyce, G. F., Keeler, E. M., Shang, B., \& GoldG. P., (2005) the lifetime burden of chronic diseases among the elderly. Health Affairs, 24(2), 18-29 (Retrieved 9/9/2020).

Kagansky, N., Berner, Y., Koren-Morang, N., Perelman, L., Knobler, Knobler, H., \& Levy, S. (2005) Poor nutritional habits are predictors of poor outcome in very old hospitalised patients. American Journal of Clinical Nutrition, 82, 784-791. 
Mba, C. J., (2004a) Population aging and survival challenges in rural Ghana. Journal of Social Development in Africa, 19(2), 90-112 (Retrieved 10/10/2020)

Mba, C. J., (2004b). Older persons of Ghana. BOLD Quarterly Journal of the International Institute of Aging 15(1) 14-18 (Retrieved 10/10/2020)

Mba, C., J., (2005) Racial differences in marital status and living arrangements of older persons in South Africa. Generations Review, 15(2), 23-31 (Retrieved 11/12/2020)

Mba, C. J., (2010) Population aging in Ghana: Research gaps and the way forward. Journal of Aging Research, 4 , 7-8 (Retrieved 11/11/2020)

McCusker, J., Kakuma, R., \& Abrahamowicz, M., (2002) Predictors of functional decline in hospitalised elderly patient: A systematic review Journal of Gerontology: Medical Sciences, 57/1(9), M569- 577. (Retrieved $11 / 11 / 2020)$

Ministry of Gender Children Social Protection (2019) Livelihood Empowerment Against Poverty. www.mogcsp.gog.gh. (Retrieved 18/01/2021)

Morley, J. E., (2001) Decreased food intake with aging, journal of Gerontology: Medical Sciences, 56, 81-88 (Retrieved 12/12/2020)

Morley, J E., (2002) Pathophysiology of anoxia, Clinical Geriatric Medicine, 18,661-673. (Retrieved 11/10/2020)

Nagler, R. M., \& Hershkovich, O., (2005). Relationships between age, drugs, oral sensorial complaints and salivary profile. Archaeological Oral Biology, 50(1), 7-16 (Retrieved 10/10/2020)

Nichlas, J. N., (2006) Windows to the heart: Creating an acute care dementia unit. New York: Springer Publishing Co., Inc.

Perissinotto, E., Pisent, C., Sergi, G., Grigoletto, F., \& Enzi, G., (2002) Anthropometric measurements in the elderly: Age and gender differences. British Journal of Nutrition, 87, 177-186 (Retrieved 11/11/2020).

Perry, L. (2001a). Screening swallowing function of patients with acute stroke Part one: identification, implementation and initial evaluation of a screening tool for use by nurses, Journal of Clinical Nursing, 10, 463-473.

Perry, L., (2001b). Screening swallowing function of patients with acute stroke. Part two: Detailed evaluation of the tool used by nurses. Journal of Clinical Nursing, 10(4), 474-481.

Perry, L., \& Mclaren, S. M., (2000). An evaluation of implementation of evidence-based guidelines for dysphagia screening and assessment following acute stroke: Phase 2 of an evidence-based practice project. Journal of Clinical Excellence, 2, 147-156.

Ree, M., Riediger, N., \& Moghadasian, M. H., (2007) Factors affecting food selection in Canadian Population. European journal of Clinical Nutrition 62(11), 1255-1262 (Retrieved 12/12/2020)

Roberts, S. B., \& Rosenberg, I., (2006), Nutrition and Aging: Changes in the Regulation of energy metabolism with aging. Physiological Review, 86, 651-667

Simmons, S. F., \& Schnelle, J. F., (2004) Improving food intake in nursing home residents with feeding assistance: A staffing analysis. Journal of Gerontology: Medical Science, 56, M790-M794 (Retrieved $12 / 11 / 2020)$

Terre, R., \& Mearin, F., (2012). Effectiveness of chin-down posture to prevent tracheal aspiration in dysphagia secondary to acquired brain injury; A video-fluoroscopy study. Neurogastroenterology and Motility. 24(5), 414-419.

United Nations (2005) World population prospect: The 2004 revised vol. 1 Comprehensive tables, New York: Population Division, Department of Economics and Social Affairs (Retrieved 12/11/2020).

United Nations (2007) World population prospect: The 2006 revised vol. 1 Comprehensive tables, New York: Population Division, Department of Economics and Social Affairs (Retrieved 12/11/2020).

Weiten, W., (2007) Psychology, themes \& Variations, $\left(7^{\text {th }}\right)$ Thomson Wadsworth, USA. Westenhoefer, J., (2005) Age and gender dependent profile of food choice. Forum Nutrition, 57, 44-51 Westergren, A., (2006). Detection of eating difficulties after stroke: A systematic review. International Nursing Review, 53, 143-149

Westergren, A., Ohlsson, O., \& Hallberg, I. R., (2002). Eating difficulties in relation to gender, length of stay and discharge to institutional care among patients in stroke rehabilitation. Disability and Rehabilitation, 24(10), 523-533.

Wilson, M-M. G., \& Morley, J. E., (2003). Invited review; Aging and energy balance, Journal of Applied Physiology, 4(95), 1728-1736. 